\title{
Experimental investigation of vortex breakdown in a coaxial swirling jet with a density difference
}

\author{
A. Adzlan*, H. Gotoda \\ Department of Mechanical Engineering, Ritsumeikan University, 1-1-1 Nojihigashi, Kusatsu, Shiga 525-8577, Japan
}

\section{H I G H L I G H T S}

- We studied a stable vortex breakdown in a variable-property coaxial swirling jet.

- A model using common nondimensional numbers is proposed to explain the following.

- The height of the stagnation point increases with increasing outer jet velocity.

- The height of the stagnation point is always lower for a denser inner jet.

- The model is fairly successful in explaining the trends observed in our study.

\section{A R T I C L E I N F O}

\section{Article history:}

Received 22 November 2011

Received in revised form

16 April 2012

Accepted 16 May 2012

Available online 23 June 2012

Keywords:

Fluid mechanics

Hydrodynamics

Laminar flow

Momentum transfer

Swirling jet

Vortex-breakdown

\begin{abstract}
A B S T R A C T
In this work we experimentally investigate the behavior of stable vortex breakdown taking place in a coaxial swirling jet with a density difference, highlighting the effect of the outer jet on the height of the stagnation point. With increasing bulk flow velocity of the outer jet, the degree of flow divergence decreases, resulting in an increase in the height of the stagnation point. This is due to a significant increase in the mean axial velocity along the centerline of the jet, which is clearly shown by particle image velocimetry (PIV). We proposed an equation to physically explain the height of the stagnation point in a coaxial swirling jet with a density difference undergoing vortex breakdown, by considering an estimate of the momentum balance in the flow, based on a simplified Navier-Stokes equation for coaxial jets with coannular flow. Even though the effect of the density difference on the height of the stagnation point is overestimated by the proposed equation, the increase with respect to the Reynolds number of the outer jet observed experimentally is in reasonably good qualitative agreement with the trend predicted by the theoretical model.
\end{abstract}

(c) 2012 Elsevier Ltd. All rights reserved.

\section{Introduction}

Vortex breakdown (VB) is one of the many intriguing phenomena that take place in swirling flows (Mak and Balabani, 2007; Mitchell and Délery, 2001; Sarpkaya, 1971; Shtern and Hussain, 1999). Even though the essential nature of VB is still under debate, it has many applications in present-day fluid science and chemical engineering including the efficient mixing of fuel and oxidant in combustors and flame stabilization (Choi et al., 2009; Huang and Yang, 2009; Mak and Balabani, 2007). Moreover, the occurrence of VB is not limited to confined flows such as in combustors and furnaces, it can also occur, for example, on the

\footnotetext{
* Corresponding author. Current address: Department of Mechanical and Manufacturing Engineering, Universiti Malaysia Sarawak, Kota Samarahan, 94300 Sarawak, Malaysia. Tel.: +6082 5833 46; fax: +6082583410.

E-mail addresses: kaafadzli@feng.unimas.my (A. Adzlan) gotoda@se.ritsumei.ac.jp (H. Gotoda).
}

wings of an aircraft. VB induces vibrations and roll moment on an aircraft, both of which are detrimental to the overall performance of the aircraft (Mitchell and Délery, 2001; Husain et al., 2003). From these examples, it is apparent that the understanding of VB will have huge fundamental and practical importance in a wide variety of fields from combustion to aeronautical engineering.

The use of swirling jets, or swirling flows with a superimposed streamwise velocity, to study the phenomenon of VB has a long history in the field of fluid mechanics. This is due to the fact that the independent variation of axial and azimuthal velocities is more easily achieved using a swirling jet than in experiments over the wings of aircraft (Billant et al., 1998). Chigier and Chervinsky (1967) showed that when VB occurs, the maximum velocity in the axial velocity profile is displaced from the center of the jet. They used a swirl generator with which the quantity of air introduced axially and tangentially can be varied to change the degree of swirl imparted into the flow. Sarpkaya (1971) used the flow of water inside a tank, with swirl generated by streamlined 